\title{
¿Son todos caciques? Curacas, principales e indios urbanos en Cajamarca (siglo XVII)
}

Ils sont tous caciques? Curacas, principales et indiens urbains à Cajamarca (XVIİ̀ siècle)

Are they all caciques? Curacas, principales and urban indians in Cajamarca (XVIIth century)

\section{Aude Argouse}

\section{OpenEdition} Journals

\section{Edición electrónica}

URL: http://journals.openedition.org/bifea/3393

DOI: 10.4000/bifea.3393

ISSN: 2076-5827

Editor

Institut Français d'Études Andines

Edición impresa

Fecha de publicación: 1 abril 2008

Paginación: 163-184

ISSN: 0303-7495

Referencia electrónica

Aude Argouse, «¿Son todos caciques? Curacas, principales e indios urbanos en Cajamarca (siglo XVII) », Bulletin de I'Institut français d'études andines [En línea], 37 (1) | 2008, Publicado el 01 octubre 2008, consultado el 10 diciembre 2020. URL : http://journals.openedition.org/bifea/3393 ; DOI : https://doi.org/10.4000/bifea.3393 


\title{
¿Son todos caciques?* Curacas, principales e indios urbanos en Cajamarca (siglo XVII)
}

\author{
Aude Argouse**
}

\begin{abstract}
Resumen
En el siglo XVII, a pesar del principio de separación entre indios y españoles, un tercio de los habitantes de Cajamarca es no-indio. En esta villa de facto, formalmente pueblo de indios, las autoridades tradicionales y el poder real comparten el espacio urbano y ocupan simbólicamente la Plaza Mayor. Las relaciones entre los representantes locales del Rey y los caciques revelan las diferencias entre los descendientes históricos de las autoridades prehispánicas, y los demás caciques que conforman una importante red de cobradores. Los caciques nobles de Cajamarca descienden de dos familias emparentadas, pero enfrentadas desde la llegada de los españoles. Estos sacan partido de esta hostilidad para limitar el poder caciquil. Los demás caciques se verán reducidos paulatinamente al difícil papel de meros recaudadores de tributos: empeñan su responsabilidad y sus bienes, pero ya no conservan el prestigio propio de su condición de autoridad tradicional.
\end{abstract}

Palabras clave: sucesión, indígenas, caciques, cobradores, villa, Cajamarca

\section{Ils sont tous caciques? Curacas, principales et indiens urbains à Cajamarca (XVII è siècle)}

\section{Résumé}

Au XVII siècle, malgré le principe de séparation entre les Indiens et les Espagnols, Cajamarca compte un tiers de ses habitants parmi les non-indiens. Dans ce qui est de facto une villa, alors qu'elle n'est

\footnotetext{
«yten porque en los repartimientos que por mi mandato se han vissitado hauia muchos yndios que por ser hijos y parientes de casiques no pagaban tasa ni servian en servicios personales y la tasa que ellos hauian de pagar (...)» (Los Reyes, 31-10-1694). Contestación del Virrey Melchior Porto Carrero Lasso de la Vega a un memorial presentado por don Alonso de Mendoza, abogado de la Real Audiencia, acerca de Juan Lulimosa (ASFL, Registro 11, ff. 40-40v)

** Estudiante de doctorado, MASCIPO, CERMA-EHESS. E-mail: oddargouse@hotmail.com
} 
sur le plan juridique qu'un pueblo de indios, autorités traditionnelles et pouvoir royal se partagent l'espace urbain et, symboliquement, occupent la Plaza Mayor. Les rapports qu'entretiennent les représentants locaux du Roi avec les caciques font apparaître une différence entre ces derniers, selon qu'ils descendent des autorités pré-hispaniques ou non, formant dans ce dernier cas un important réseau de percepteurs de l'impôt. Les caciques nobles de Cajamarca descendent de deux familles apparentées qui n'ont cessé de s'affronter depuis l'arrivée des Espagnols. Ces derniers jouent de cet antagonisme pour limiter le pouvoir des caciques. Les autres caciques se virent réduits, petit à petit, au rôle pénible de simple percepteur. Engageant leur responsabilité et leurs biens, ils ne bénéficient plus du prestige attaché à leur condition d'autorité traditionnelle.

Mots clés : succession, indiens, caciques, percepteurs, ville, Cajamarca

\title{
Are they all caciques? Curacas, principales and urban indians in Cajamarca (XVII ${ }^{\text {th }}$ century)
}

\begin{abstract}
In the XVIIth century, in spite of the principle of separation between Indians and Spaniards, one third of the inhabitants of Cajamarca was non-Indian. In this de facto "villa", formally a "pueblo de indios", traditional authorities and royal power shared the urban space, and were symbolically situated on the central plaza. The relationships between the local representatives of the King and the caciques highlighted the differences between the caciques, according to their being noble or belonging to the important web of tribute collectors. The noble caciques of Cajamarca were descended from two families, albeit related to each other, that were pitted against one another with the arrival of the Spaniards, who took advantage of this hostility to restrict their power. In the meantime, the other caciques become mere tribute collectors, whose responsibility involved their own goods, lost their traditional prestige.
\end{abstract}

Key Words: inheritance, Indians, caciques, tax collectors, city, Cajamarca

\section{INTRODUCCIÓN}

El estudio de los testamentos de indígenas cajamarquinos, redactados a lo largo del siglo XVII por los escribanos del cabildo de naturales1, revela la presencia de individuos que llegaron a comprar un pedazo de solar o lo heredaron de sus antecesores, el cual estaba ubicado en la traza de la villa (Espinoza Soriano, 2002). Estos «testamentos de indios» encontrados en el Archivo Departamental de Cajamarca, forman un conjunto de documentos cuya mayoría se halla en el legajo de un solo escribano del Cabildo2, mientras que los demás están dispersos en los protocolos de varios notarios o de otros escribanos del Cabildo de los naturales de Cajamarca. Aunque la historiografía andina, por lo general, presenta el mundo

1 Hasta 1808, hubo solo un cabildo de indios en Cajamarca y no hubo cabildo de españoles, aunque éste había sido reclamado varias veces. Entre 1808 y 1812, hubo dos cabildos, uno de indios y otro de españoles que funcionaron a la vez. Véase Pereyra Plasencia (1996).

2 Se trata de Pascual Culqui Rayco, escribano del Cabildo de los naturales de Cajamarca, entre 1675 y 1688. Su legajo $n^{\circ}$ 41, cuenta con más de 350 testamentos y memorias de indios. También sus predecesores, como p. e. Muxen y Llanos, redactaron actas a petición de indígenas, inclusive testamentos. En cuanto a escribanos españoles, parece que Pedro de Saldaña Pinedo colaboró con los indígenas, según el juicio de residencia del Corregidor Antonio de Quintanilla (AGI, Escribanía de Cámara, 535B). Sin embargo, sus libros no contienen muchos testamentos o memorias de indios. 
indígena como «mundo del campo» mientras el mundo español es visto como mundo urbano, estos indígenas testadores tienen algo en común: son indios urbanos 3 y dependen de varios caciques. Así, el paradigma que representa Cajamarca en la utilización de un espacio urbano de origen prehispánico por los españoles (Gutiérrez, 1992), parece en realidad esconder la creación de un espacio moderno dentro del cual se hallan individuos con patrimonios, y no grupos o comunidades (Ramírez, 2001)4 con tierras colectivas. Los indios urbanos tienen su casa de vivienda dentro de la traza de la villa y sus chacaras, fuera de ella. Estos indios urbanos han sido convertidos al cristianismo por los padres franciscanos de Cajamarca y dictaron testamentos muy parecidos a los de los españoles. Salvo que al encabezar su testamento, siempre especificaron a qué ayllu, pachaca o guaranga pertenecían5, lo que nos permite conocer el origen de cada individuo.

La dicotomía entre «españoles urbanos» e «indios del campo» es cuestionada desde unos quince años por algunos estudios sobre villas y ciudades de los Andes, que ponen de relieve la existencia de estos indios urbanos6.

Para caracterizar la índole de la relación que tenían con sus caciques en el siglo XVII, tenemos que conocer a los caciques de Cajamarca. Nos dimos cuenta de que la tarea no era fácil al leer la súplica de Juan de Lulimosa, en 1694, cuando afirma ser Cacique por ser descendiente de unos importantes caciques de Cajamarca, y reclama los privilegios del cacicazgo, en particular la exención del tributo. El resultado de tal comportamiento sería que una mayoría de los indios de Cajamarca, al estar vinculados a uno que otro Cacique, podría gozar de sus privilegios, no pagar tributo, tampoco cumplir con la mita, o servicio personal. Lo denuncia el Virrey en 1694, diciendo que la carga del tributo cae sobre los indios más pobres de Cajamarca, que no logran pagarla. Asi, la situación particular de Cajamarca, como pueblo de indios donde se afincaron muchos españoles, revela la existencia de varios tipos de caciques en el siglo XVII.

\section{UN PUEBLO DE INDIOS CON POBLACIÓN ESPAÑOLA}

San Antonio de Cajamarca, cabeza del repartimiento de Cajamarca, está ubicado en los Andes bajos del norte del Perú actual, a unos 2800 msnm, en el sur del departamento de Cajamarca, a unos $950 \mathrm{~km}$ al norte de Lima y a $250 \mathrm{~km}$ del Océano Pacífico (fig. 1). Se ubica en el antiguo reino de Cuismanco, y fue probablemente un centro importante de este reino, sin que sepamos si fuera realmente la cabecera del reino o no (Silva Santisteban, 1985). Cuando los incas lo conquistaron, transformaron Cajamarca en un centro más importante de producción textil, con aposentos y crearon la huamani, o provincia de Cajamarca.

3 Uno de los principales trabajos sobre el tema es el de Minchom (1994), sobre Quito. Véase también Poloni-Simard (1999: 90-95) sobre Cuenca, en Ecuador. Sobre Lima, Charney (1988).

4 Poloni-Simard (1999: 94) señala que no se sabe sobre qué fundamento se agrupó la población indígena de Cuenca, pero afirma que «las parroquias indígenas no son prolongaciones, substitutos o resurgencias de las comunidades».

5 Sobre este punto particular Remy Simatovic (1992: 73), en su introducción a las visitas a Cajamarca hechas en 1572-1578, nota que la palabra ayllu no era usada por los indios de Cajamarca en el siglo XVI. Solo se empleaban las palabras Guarangas y Pachacas. La noción de ayllu fue reintroducida en Cajamarca por los españoles, después de haber sido utilizada por los incas, y en los testamentos cajamarquinos ambas palabras se usan. Cabe decir que una guaranga es una entidad sociopolitíca, constituida de varias pachacas. El término guaranga significa 1000, y el de pachaca, 100. «Ambos términos fueron utilizados en la división decimal de la población del Tahuantinsuyu con fines tributarios. Dentro de un esquema ideal, cada pachaca estaría compuesta por 100 tributarios y cada guaranga comprendería 10 pachacas, sin embargo este no siempre es exacto».

6 En particular, Minchom (1994). Sobre Cajamarca y Trujillo, Noack (2001). 


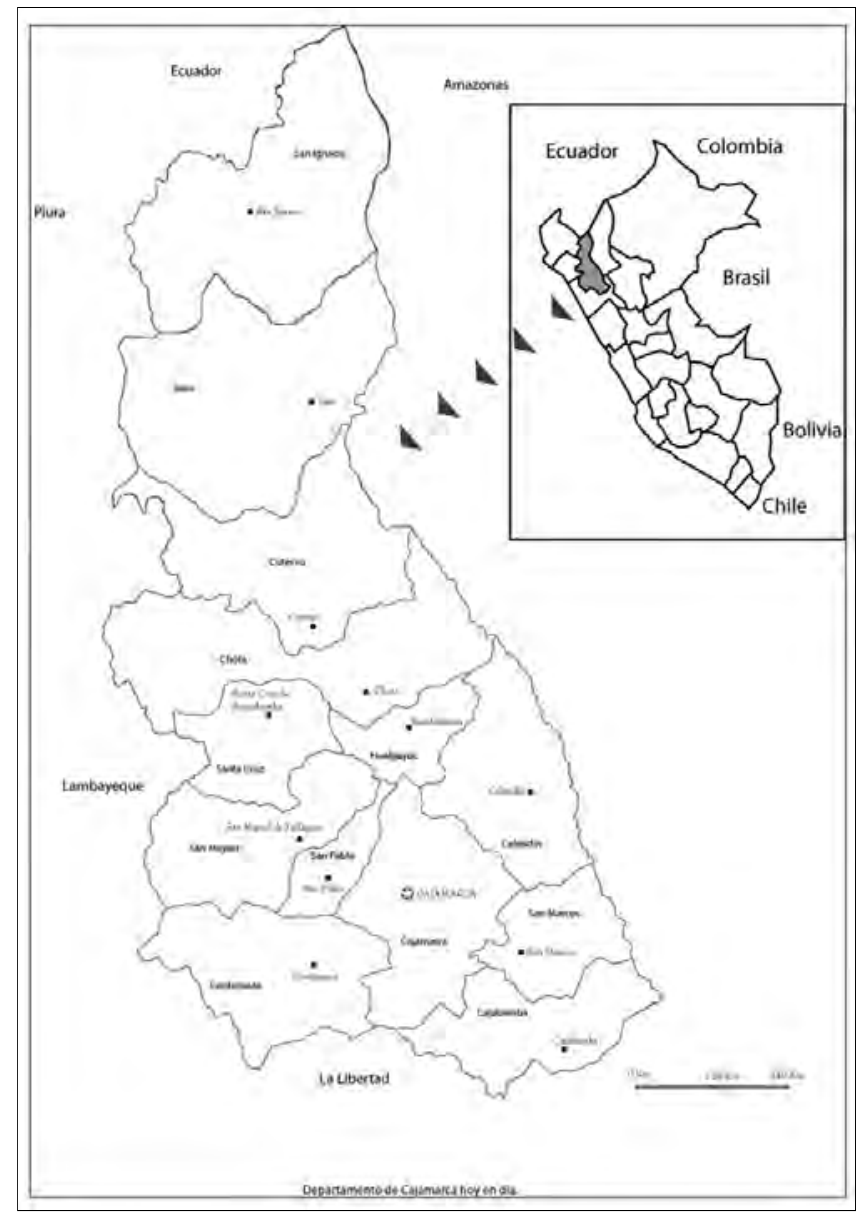

Figura 1 - Mapa de ubicación de Cajamarca en la Audiencia de Lima. Fines del siglo XVIII

Conservaron el nombre de Cuismanco para una de las guarangas7 que formaban la huamani de Cajamarca. Estas guarangas eran siete (Bambamarca, Chuquimango, Cajamarca, Chondal, Guzmango, Pomamarca y Mitimaes) en el tiempo de los incas, quienes crearon la guaranga de Mitimaes. Después, la huamani incaica de Cajamarca, al ser conquistada por los españoles, vino a ser la provincia de Cajamarca, o de las Siete Guarangas, y fue una de las tres provincias que formaron el Corregimiento de Cajamara8.

Cajamarca, entonces asiento, pasó a ser pueblo de indios en 1565, cuando los españoles crearon la reducción de San Antonio de Cajamarca. Los indígenas allí reducidos tenían varios orígenes, sin embargo según la visita hecha en 1572, el $50 \%$ es originario de la guaranga de Cajamarca. La otra mitad se reparte de esta forma:

7 La identificación de las guarangas y pachacas con localidades geográficas es muy compleja (Remy Simativic, 1992).

8 Los demás son Guambos, al norte, y Guamachuco al sur. Para una explicación completa de la distribución en guarangas, pachacas y parcialidades cajamarquinas, véase Remy Simativic (1992). 
¿Son todos caciques? Curacas, principales e indios urbanos en Cajamarca (siglo XVII)

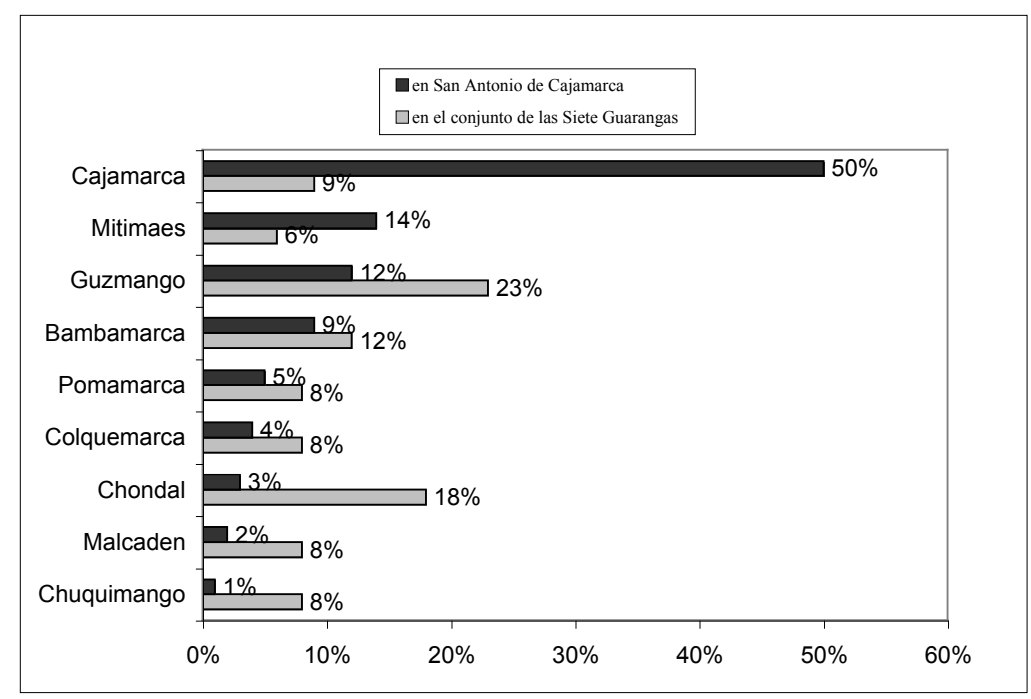

Figura 2 - Repartición de los indios según su guaranga de origen 1572-1578

Fuente: Remy Simatovic (1992)

Los documentos del siglo XVII muestran que la población de Cajamarca ha cambiado y que no se mantuvo dicha proporción. En 1686, la villa de Cajamarca, visitada por los franciscanos, presenta la repartición indígena siguiente:

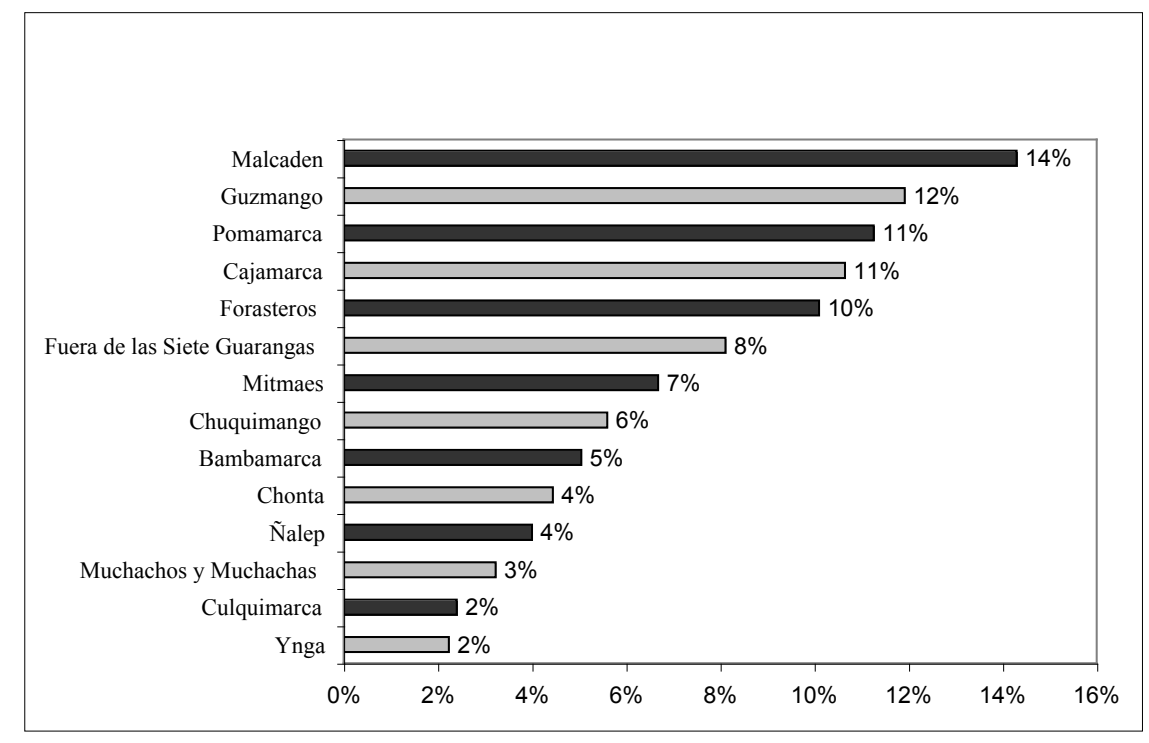

Figura 3 - Repartición de los indios según sus guarangas originales, San Antonio de Cajamarca, 1686 Fuente : Archivo San Francisco de Lima, registro 11, visita y padrón de los indios por los franciscanos en 1686, ff. 191-424. Elaboración A. Argouse, 2007 
Se ve que la composición de la población indígena de Cajamarca ha cambiado, y que se han introducido en el pueblo una diversidad étnica muy importante. Sin embargo, la numeración de la población indígena que vive en Cajamarca no es precisa. Tampoco lo es la del Corregimiento, y de la provincia del mismo nombre, que también llaman las Siete Guarangas. La cifras dadas por varias fuentes no se pueden comparar porque no representan la misma área9. A lo largo del siglo XVII, varias visitas arrojan varias cifras (Hampe Martínez, 1986-1987). En cuanto a los indígenas que vivían dentro del casco urbano, no encontramos visita alguna, aparte de la hecha en 1686. Así que hace falta buscar la información en diversas fuentes documentales, con las cuales llegamos a unos 4000 indios que vivían en la traza de la villa alrededor de 1650 y unos 6000 a fines del siglo XVII10. También se señala, para el año 1699, la cifra de 7000 indios en la traza de la villa. Esta cifra parece un poco exagerada porque está citada en una solicitud para que se nombren más curas de indios (Archivo del Convento San Francisco de Lima, registro $n^{\circ} 11$, f. 78 v.). Es muy posible que el suplicante haya inflado su estimación para obtener su provisión11.

A pesar de la prohibición hecha por el Real Patronato de que los españoles viviesen en lugares de indios, se nota la presencia de una población española importante en el «pueblo de indios» que era Cajamarca12. La denominación de pueblo de indios significaba que los españoles no tenían derecho a residir en él. Sin embargo, el pueblo de Cajamarca tal como se titulaba a lo largo de los tres siglos de dominación española, ya en el siglo XVII se volvió una villa de facto (Espinoza Soriano, 2002). La existencia de un sector de la población cajamarquina mestiza, biológica y culturamente, es por supuesto conocida, pero no es el objeto del trabajo presente13.

Del punto de vista jurídico, un pueblo de indios debía tener un cabildo de indios, con dos alcaldes, dos regidores, un escribano, un pregonero, y una doctrina con «curas de indios». También, se vetaba la presencia de españoles, ellos no podían comprar tierras, ni tener negocios con los indios. Esto era la applicación de la separación entre la República de españoles y la República de indios. Los motivos que tuvieron esos españoles para vivir en Cajamarca se pueden adivinar por los comentarios que hacían los cronistas sobre el buen clima, la fertilidad de la tierra, y la abundante mano de obra indígena (Ravines,

9 Hay cifras de 1532 (2 000 almas en el Pueblo de Cajamarca), de 1540 (493 tributarios en el repartimiento de Cajamarca), de 1567 (5 169 tributarios). Las visitas de 1571-1578 contabilizan 28915 almas en el repartimiento y 5008 tributarios. En 1593, según Toribio Mogrovejo, cuentan 5624 almas en la villa de Cajamarca y 835 tributarios. En 1611, hay 21639 almas de indios en el repartimiento y 4000 tributarios. El número de tributarios del repartimiento baja hasta 2658 en el año 1658. En cuanto al Corregimiento, una cifra de 1583, dada por Silvio Zavala (1992 [1935]), nos indica la presencia de 43195 personas. Vásquez de Espinosa (1969 [1628) el año 1611, revela la presencia de 36817 personas.

10 Estas cifras proceden de diferentes fuentes y estimaciones, en particular Vargas Ugarte (1986), así como los autores citados previamente.

11 Debemos señalar también el problema de la desaparición de los indígenas, sea esta física o fiscal. En efecto, tengo algunos casos de indios que, a partir de los años 1660, dicen ser mestizos, y así salen del padrón de indios. En torno a la desaparición física, dos elementos dan fe de ella: el mandamiento hecho a Ygnacio de Valdez para recoger el tributo de los indios de Cajamarca que están en otra provincia, en 1645 (ADC, serie Corregimientos, Testimonios, s/n). Además, en AGI, Lima 171, Melchor Carua Rayco recuerda lo difícil que le resulta el cobro del tributo, por haber más de 600 indios ausentes, entre 1662-1665.

12 En el caso de la numeración de la población española de Cajamarca, se nota que en el año 1635, se hizo un censo para conocerla. Sin embargo el censo no se hizo, apuntando los nombres de las personas por lo cual la cifra presentada de 645 españoles está cuestionada hasta por la administración real (AGl, Escribanía de Cámara, $516 \mathrm{~A})$.

13 Una cédula real de 1635 afirma que la villa de Cajamarca cuenta con 1935 personas que no son indígenas (645 españoles, 741 mestizos, 548 mulatos, negros libres, esclavos y gente de servicio), según el padrón hecho por Melchor del Billar, notario (AGl, Escribanía de Cámara, 516 A: f. 1). En el mismo documento (f. 10v), encontramos la cifra de la población total de la villa de Cajamarca, que es de alrededor de 10000 personas para el año de 1666. 
1986). Los españoles de Cajamarca eran en mayoría hacendados y obrajeros. Además, al situarse Cajamarca en el camino de Chachapoyas, en el eje costa-selva, y en la ruta que va de Quito a Cusco, por la vía de la sierra, contaba con un tambo muy importante, y una presencia numerosa de tratantes y mercaderes. Era un centro de comercio muy activo, donde transitaban muchos arrieros (AGN, Superior Gobierno, L. 4, c. 45) 14. Eso contribuye a explicar la presencia española importante y permanente en la villa. En 1632, vivían en Cajamarca unos 662 habitantes españoles, sin los pasajeros y comerciantes (con 141 esclavos y 8 mulatos libres) (AGI, Lima 303, in Espinoza Soriano, 2002). Otra cifra que incluye a los mestizos para el año 1635 revela la presencia de 645 personas españolas, 742 mestizos (hombres y mujeres) y 548 esclavos, negros y mulatos libres y gente de servicio. En 1644, cuenta con unos 900 personas españolas (Espinoza Soriano, 2002), pero ya en 1675 la cifra ha subido a 4000 españoles sin los pasajeros y comerciantes (ASFL, registro 11: f. 78v), para una población total de más de 10000 personas en la villa (año 1667) (AGI, Escribanía de Cámara: 516 A).

En cuanto a los administradores, tales como alguaciles mayores, tenientes, escribanos y Corregidor, parece que la nominación del Corregidor por el Rey era un tipo de recompensa: por ejemplo, el Rey señala el Corregimiento de Cajamarca a don Antonio de Ontañeda, se dice que por haber sido un buen administrador15. A continuación, el Corregidor designaba a sus administradores. Algunos podían haber venido con el mismo Corregidor o proceder del mismo lugar. Pero estos administradores del corregimiento no podían comprar tierras en él. La ley les prohibía totalmente negociar cualquier cosa con los indígenas. Sin embargo, encontramos apellidos que tienen una recurrencia que nos indica que, aunque eran administradores, se quedaron en Cajamarca toda su vida16. Está claro que los españoles no cumplieron con la ley, y se afincaron comprando tierras, que trataron de legalizar 17. Pedro de Meneses, en la composición de tierras que hace en Cajamarca en 1644, revela que la presencia española tiene una fuerte importancia económica y que, de marcharse, se hundiría la economía del lugar18. A mi parecer, aquellos españoles llegaron a Cajamarca cuando la situación no estaba tan clara (entre los años 1625 y 1660), aprovechando el conflicto que oponía a los franciscanos de Cajamarca y al obispo de Trujillo sobre el hecho de ser ilícita su presencia por no tener cura de españoles.

En efecto, para legalizar su presencia en este pueblo de indios, los españoles hicieron composiciones de tierras (1644), y para legitimarla, llegaron a edificar una parroquia de

14 En 1662, el mercader Miguel Navarro viaja a Cajamarca para recoger su plata por la ropa que había distribuido y vendido aquí. Véase también, Vásquez de Espinosa (1969 [1628: 144), «(...) hay muchas tiendas de mercaderes y tratantes, por ser lugar grande y de mucho trato, y camino real por la sierra para todos los que vienen del Nuevo Reino y de Quito con mercaderías para el Cuzco, Potosí y toda la tierra de arriba, y así tiene la comunidad y cabildo de los indios de esta villa un mesón muy grande y capaz y bien hecho para que en él se aposenten todos los arrieros y mercaderes con mucho servicio de indios, tambero y alguaciles para el servicio de los españoles (...)».

15 Hasta 1626, el nombramiento del Corregidor estaba a cargo del virrey del Perú. A partir de esta fecha, fueron designados directamente por la Corona, sobre proposición del Virrey y en 1642, la Corona ya nombraba directamente al corregidor de Cajamarca (Pereyra Plasencia, 1996).

16 Todavía falta un estudio sobre las relaciones que los españoles de Cajamarca tenían con la Audiencia de Lima. Sin embargo, véase Cuesta (1988), quien reproduce una carta al Consejo de Indias en 1611, que denuncia que el corregidor de Cajamarca es pariente del Virrey. También Antonio de Quintanilla, Corregidor entre 1663 y 1675 mantiene estrechas relaciones con los funcionarios de Los Reyes.

17 Véase la composición de tierras hecha a partir de 1631 por Pedro de Meneses, y luego cancelada por haberse hecho con fraude (AGN, títulos de propiedad, 1644, L. 34, c. 649: ff. 50 in Figueroa Luna, 1993).

18 López de Caravantes, en 1630, indica que «hay más de ducientas y cinquenta estancias de ganados en que se crían vacas, ovejas, caballos, mulas y puercos, de que se provee la ciudad de los Reyes y se da lana a todos los obrajes para las bayetas, cordellates, sayales, pañetes y frezadas que labran...», citado por Pereyra Plasencia (1996: 184) 
españoles, Santa Catalina. La construcción definitiva de la iglesia empezó en 1682, al cabo de casi setenta años de lucha entre los franciscanos regulares de Cajamarca y el obispo de Trujillo.

En 1616, el corregimiento de Cajamarca dejó de pertenecer al obispado de Lima y pasó bajo el control del obispo de Trujillo. Este se dio cuenta de que en Cajamarca había un número importante de españoles. El único cura que les atendía vivía en Condebamba, a catorce leguas de la villa. Por lo tanto, la mayoría de los españoles de Cajamarca no recibían los sacramentos y asistían a las misas destinadas a los indígenas, en la mayor confusión. Sin embargo, la idea de acoger a un cura de españoles no complacía a los franciscanos encargados de la doctrina de indios, y así se inició un conflicto de intereses entre los religiosos del convento franciscano de Cajamarca y el obispo de la ciudad de Trujillo. Los franciscanos de Cajamarca, no querían compartir el poder que tenían y la introducción de otros curas significaba que perdían el privilegio de ser los únicos religiosos de Cajamarca, encargados de doctrinar a los feligreses indígenas. Es posible que temieran perder su estipendio. El argumento principal aducido por los franciscanos de Cajamarca era que la presencia española tenía por consecuencia que los indios ya no tendrían tiempo de ir a misa porque estarían trabajando en las casas de españoles (AGI, Escribanía de Cámara, 516A)19. Sin embargo, el 23 de abril de 1623, el Rey otorgaba a los españoles la asistencia de un cura. Pero era un cura sin parroquia. Para respetar la ley de separación entre españoles e indios, empezó a decir misa en el Hospital de los indios. La situación se volvió rápidamente insostenible y, de nuevo, pidieron la edificación de una parroquia propria. En el año 1644, le fue recordado al corregidor de Cajamarca que no podía edificar parroquia de españoles. Sin embargo, a principios de los años sesenta, se reactivó la pelea judicial, hasta llegar al Consejo de Indias en 1668. Así que el siglo XVII presenció la construcción, el derribo y la reconstrucción de edificios dedicados a la parroquia de españoles (ASFL, Registro 11)20. Tres veces se echó abajo la edificación, con los consiguientes escándalos²1.

Sin embargo, aunque los residentes españoles llegaron a tener una parroquia en 1682, y unos títulos jurídicos a lo largo del siglo XVII, o sea legitimar y legalizar su presencia, no lograron tener un cabildo. Era entonces el Corregidor, asistido por otros funcionarios, quien estaba encargado de la justicia para los no-indígenas. En cuanto a la justicia de los indios, la administaban sus caciques (Díaz Rementería, 1977) y el cabildo de indios.

\section{EL ESPACIO URBANO COMPARTIDO}

Según Vázquez de Espinosa (1969 [1628]) el virreinato del Perú contaba con 173 ciudades y 57 villas. La formación de las ciudades y villas americanas ha sido inspirada directamente por una concepción europea de la ciudad. Se trata de una «extensión transatlántica del

19 El documento contiene también un memorial de los caciques de Cajamarca quienes explican los motivos por los que se oponen a la edificación de una parroquia de españoles en Cajamarca.

20 El registro contiene varios memoriales y probanzas de los curas franciscanos de Cajamarca y Trujillo que se opusieron a la erección de la parroquia de españoles. Este registro se completa con Escribania 516 A del AGl, año 1667.

21 El tiempo ha sido un componente muy importante del conflicto. Al mismo tiempo que solicitaban al Virrey o al Rey el derecho de edificar una parroquia, ya empezaban a edificarla. Y cuando llegaba la denegación, ya era caduca porque la súplica ya era otra: el permiso para derribar la construcción. De esta manera, se armó el escándalo tres veces, iporque tuvieron que echar abajo el edificio tres veces! 
urbanismo europeo» (Kubler, 1957). Parece entonces que, como en el campo del derecho, se dio una «recepción», y luego una transformación del modelo europeo:

«Si la ciudad europea puede considerarse como centrípeta por atraer hacia sí las fuentes económicas de la región, la ciudad americana, por el contrario, funcionó más como fuerza centrífuga en la explotación de las inmediaciones» (Aguilera Rojas, 1994).

Según el modelo europeo, la ciudad está tradicionalmente relacionada con el poder (polis y civis), y se opone al campo. Mundo urbano versus mundo del campo, civilización versus barbarie. La polis está también asociada a la idea de orden, y hasta cierto punto, puede identificarse con el Estado por ser su reproducción a un nivel más pequeño (Monnet, 1999). Los estudios sobre la ciudad en América Latina nos permite darnos cuenta de la especificidad de las ciudades latinoamericanas22. Casi todos empiezan por una reseña de los orígenes griegos y romanos de la ciudad (civis, polis), de las influencias del Renacimiento italiano, del desarrollo de un modelo de Ciudad ideal (Vayssière \& Le Flem, 1978 ). Evocan también la construcción sui generis de la ciudad en América Latina, salvo en el caso brasileño. Estos estudios destacan el papel de la ciudad como símbolo e instrumento de la Conquista (Musset, 2002). La construcción de una ciudad empieza siguiendo la pauta de la retícula ortogonal, y también de la cuadrícula cuando las cuadras tienen el mismo tamaño. En efecto, una de las particularidades del modelo es la repartición por igual de los solares urbanos, lo que da a la ciudad un perfil jerarquizado e igualitario. La plaza mayor (Ricard, 1947) es el centro político de la ciudad, pero queda una duda sobre su consideración por parte de la población. En efecto, según los documentos notariales cajamarquinos (compra, venta y testamentos), raramente se hace referencia a la plaza mayor para señalar un solar o una casa.

Sin embargo, alrededor de la plaza mayor, ciertos solares urbanos están reservados para la iglesia parroquial, la casa del cabildo, la cárcel, u «otra utilización simbólica»23. Esta plaza abierta es el rostro de la ciudad, su centro de conviviencia urbana (Bonet Correa, 1978: 82)24. Según Chevalier, la plaza mayor es el centro de una comunidad urbana, es la expresión material y concreta de una institución (Chevalier, 1978). De las 38 ciudades y villas dibujadas por Guaman Poma, 37 están representadas por su plaza mayor. Guaman Poma dibujó Cajamarca (fig. 4) con su plaza mayor, y la representó con los símbolos esperados: la plaza central, el convento franciscano y el encuentro entre Atahuallpa y Pizarro, reelaborado bajo la forma propia de la sociabilidad colonial. Sin embargo, no existe mapa de Cajamarca antes del que mandó realizar Martínez Compañón a fines del siglo XVIII. En esta representación (fig. 5), se notan los símbolos de la repartición del espacio urbano entre las casas del Cabildo y la del Cacique que se hallaban en la Plaza Mayor. Además, la casa del Corregidor también estaba ubicada en la plaza mayor, según testimonios contenidos en un registro franciscano y en el relato de Vázquez de Espinosa. Así como la parroquia de San Antonio de Cajamarca, parroquia principal de indios25, y

22 Christophe Alexander, in Aguilera Rojas (1994). Su artículo se titula «A City is not a tree», in The Architectural Form (1965).

23 Toda la ciudad está articulada alrededor de la plaza central, según las ordenanzas de Felipe II de 1573.

24 La plaza mayor medieval no siempre se ubicaba en el centro del poblado. En España, tuvo lugar en Valladolid el cambio formal de las plazas mayores. A consecuencia de un incendio que arrasó 440 de sus 670 casas, se pasó de un trazado irregular al famoso plano cuadriculado en 1561.

25 Existían otras cuatro parroquias en la villa de Cajamarca. En 1686, se señalan las parroquias de San Pedro, San José, San Sebastián. También existía la parroquia de San Lucas (ASFL, registro n 11). Vázquez de Espinosa (1628: 279): «Este cabildo está en la plaza que es muy grande, y a otro lado está la guayrona, que son otras casas muy buenas y grandes para pasajeros mas graves (...); luego está la casa del Corregidor, donde tiene muchos indios que hacen y 
Santa Catalina, parroquia de españoles, también se encontraban en la plaza a fines del siglo XVII, cada una en un lado, en una simetría manifiesta y sugerente 26.

Resulta que el espacio urbano estaba compartido, y a diferencia de lo que describe PoloniSimard para Cuenca, no parece haber existido un centro español y una periferia indígena, más bien una coexistencia de las residencias y casas de vivienda en el casco urbano. San Antonio de Cajamarca, pueblo de origen prehispánico, luego reducción de indios, fue modelado, a lo largo del siglo XVII, como una villa hispanoamericana, por una presencia española que modificó el rostro del lugar. Se puede imaginar fácilmente que en la villa, indígenas, caciques y españoles debieron

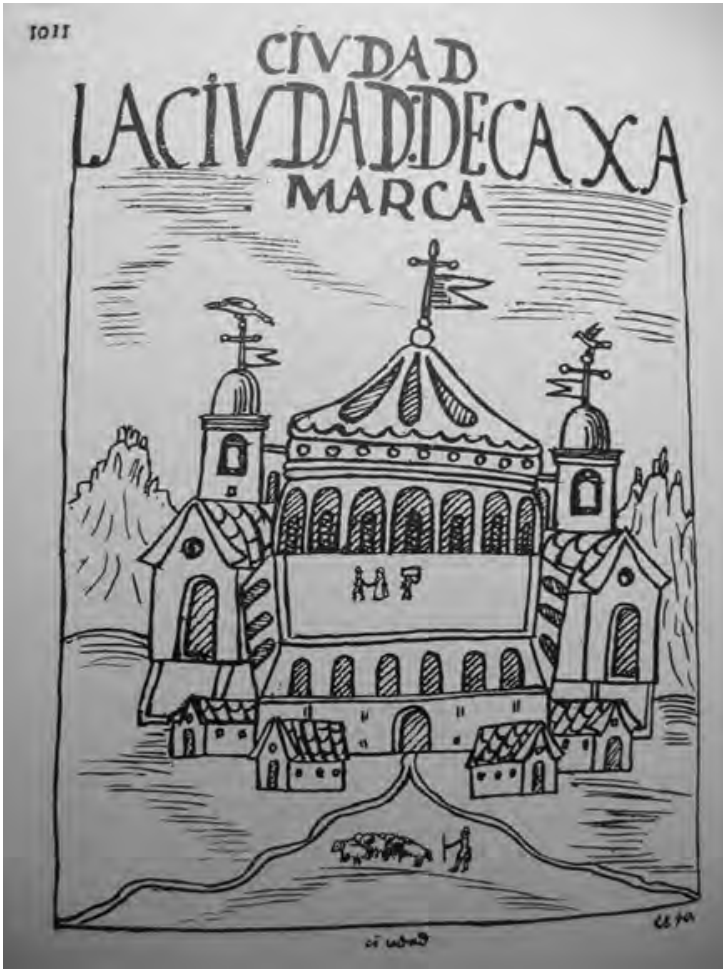

Figura 4 - Ciudad de Cajamarca

Huaman Poma de Ayala, 1936 [1613]: 1022 compartir el espacio urbano, edificando cada uno sus casas en la traza de la villa.

En este marco, quisiera destacar las relaciones de las autoridades indígenas locales con el poder español. En efecto, en los pueblos de indios tales como Cajamarca, las autoridades indígenas son las que se encargaban del gobierno de los indígenas, o sea de los «asuntos de la república de indios». Por lo tanto, en esta villa hispano-indígena de facto, que atrae a un poblamiento plural icómo se comparte el poder entre las autoridades indígenas y las autoridades españolas?

\section{REPARTICIÓN DEL PODER}

De forma escueta, se puede decir que la administración de la villa y del corregimiento se hacía por las autoridades indígenas, caciques y cabildo, conjuntamente con el poder colonial, y su representante, el Corregidor. Parece que el poder colonial administraba a las poblaciones indígenas organizadas en pueblos toledanos o en parroquias dentro de la villa, mientras que los caciques las administraban según otro orden, que es orden propio, basado en los antiguos ayllus, pachacas y guarangas. A mi entender, existía entonces un orden indígena propio, revelado por la existencia de los caciques cajamarquinos.

Se suele decir que los caciques de Guzmango han sido los antiguos señores de Cajamarca y que todavía bajo el dominio español, destaca la importancia de estos caciques que forman parte de la nobleza indígena de Cajamarca (Ramírez, 1998; 2002; Silva Santisteban, 1986).

labran paños de cumbe»; 280: «Luego está la casa del cacique inmediata a la del Corregidor y cerca del convento que solo hay una calle en medio, y en ella está la sala que Atabalipa rey señaló que llenaría de oro por su rescate (...); según me dijo el cacique Don Felipe (= se trata de Carua Rayco) permanece y permanecerá aquella sala sin tocarla en memoria de la prisión y muerte de Atabalipa».

26 Sin embargo, se debe precisar que en la documentación de la época, principalmente las compra-ventas, no se hace referencia a dicha plaza para localizar las casas. Estas se deslindan por otras casas o, de vez en cuando, por el río San Lucas, o tal parroquia. 


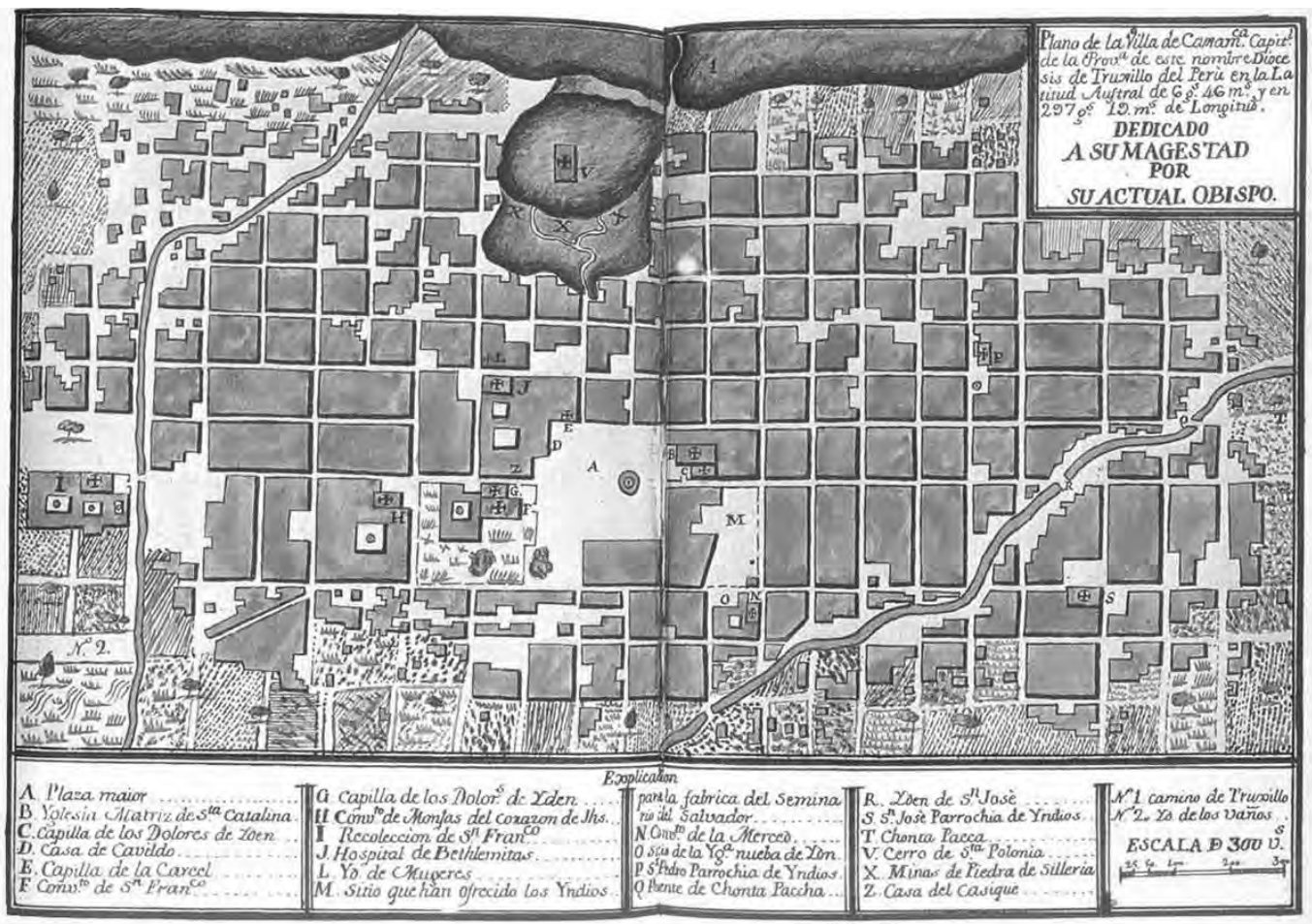

Figura 5 - Trujillo del Perú en el siglo XVIII (folio 88r)

Baltazar Jaime Martinez, 1978 [1782-1787]

Sin embargo, aparece en un análisis que Noack hizo a partir de la documentación notarial del siglo XVI, en particular del testamento de Melchior Carua Rayco, cacique de las Siete Guarangas, que los caciques de Guzmango habían hecho unas declaraciones contradictorias en las primeras visitas realizadas por los españoles (Noack, 2001). La hipótesis es que habían intentado crear un mundo, en ventaja suya, en este momento, y no solo describir la realidad como la conocían. Los españoles no trataron de rectificar esto, si es que se dieron cuenta de ello. A los curacas andinos, los españoles les llamaron caciques, palabra importada del Caribe, y los reconocieron como mediadores entre los indios y los colonos. Por lo tanto, las relaciones de poder entre los españoles y los caciques en el siglo XVII pueden ser examinadas, tomando en cuenta los conflictos que surgieron entre los caciques de Cajamarca en el siglo anterior. Parece que los españoles aprovecharon estas tensiones entre unos y otros para gobernar la provincia de Cajamarca.

A partir de algunos testamentos de caciques y de cobradores cajamarquinos, se pueden reconstruir las genealogías de sus familias en el siglo XVII. Aparecen dinastías caciquiles y tres tipos de caciques, que voy a tratar de presentar aquí. Primero, los descendientes de Felipe Carua Rayco, que son caciques principales, gobernadores de las Siete Guarangas, antiguamente señores de Cuismanco. Segundo, los caciques gobernadores del Corregimiento de Cajamarca, «por título de Su Magestad», descendientes de Cristóbal Xulca Poma y de Pedro Angas Napón. Y en tercer lugar, vendrán los demás caciques cobradores, principales y mandones de las guarangas, ayllus y parcialidades de Cajamarca, quienes forman una red impresionante de cobradores. Éstos eran los responsables de la cobranza del tributo hasta el nivel de la pachaca. Los caciques designados por su antecesor eran confirmados por el 
poder español. Además, algunos del tercer tipo pueden haberse autodesignado, cuando afirman que cobran el tributo y que son descendientes de un Cacique.

\section{LOS CARHUA RAYCO: CACIQUES PRINCIPALES DE LAS SIETE GUARANGAS}

Cuando los españoles trataron de entender la genealogía de los Carua Rayco, los habitantes de la guaranga de Guzmango, en la cual dijeron tener sus antepasados, solo pudieron recordar a dos hermanos que fueron jefes de Guzmango (Guzmango Cápac) en el tiempo del Inca: Concacax y Cosa Tongo (Ramírez, 2002). El hijo de Concacax, Chup Tongo había sido educado en el Cusco y fue el tutor del Inca Túpac Inca Yupanqui, el emperador que sometió Cajamarca, llamado entonces Reino de Guzmango, alrededor del año 1460. Después de haber servido al Inca y a su hijo, Guayna Cápac, Chup Tongo volvió a Guzmango. Sin embargo, la lucha que empezó con la sucesión de Guayna Cápac, fallecido en 1526-1527, dividía a los hijos de Chup Tongo. Así, Carua Tongo se puso del lado de Atahuallpa, mientras Carua Rayco entraba en las filas de Huáscar. Pero Chup Tongo murió el día 16 de noviembre de 1532, durante el famoso encuentro entre Atahuallpa y Pizarro en Cajamarca.

Después de la muerte del Inca, y cuando los españoles impusieron el orden colonial, Carua Rayco pasó a ser cacique de las Siete Guarangas, es decir el cacique de toda la provincia de Cajamarca (Espinosa Soriano, 1967). Fue bautizado, recibió el nombre de Felipe, y fue confirmado por el encomendero Melchor Verdugo en su título de señor y Cacique principal de Cajamarca en el año 1538. Después de su muerte en 1543, el cacicazgo pasó a su hijo, Melchior. Pero, por ser muchacho, fue dado por interín a Diego Zuplián y Pedro Angas Napón. Sin embargo, cuando quiso recuperar el cacicazgo en 1560, por haber muerto Diego Zuplián, Melchior Carua Rayco fue despojado por Pedro Angas Napón. A la muerte de Angas Napón alrededor de 1563, y por petición de los indios de Cajamarca, el recién llegado corregidor de Cajamarca don Pedro Juárez de Illánez, designó a Melchior Carua Rayco como «cacique principal de las Siete Guarangas de Cajamarca». Sin embargo, la situación no quedaba clara porque, como lo subraya Ramírez (2002), cuando los indígenas se dieron cuenta de que los españoles no entendían nada de los usos de sucesión de los curacas andinos, trataron de socavar el poder de Melchior Carua Rayco. Don Cristóbal Xulca Poma y don Sancho Xulca Poma, dos primos, pretendieron tener derecho al cacicazgo. Cuando el visitador Doctor Gregorio González de Cuenca visitó la provincia de Cajamarca en 1567, decidió entonces nombrar como Cacique a don Antonio Chup Lingón, hijo del cacique Chup Tongo, muerto en 1532, para acabar con las numerosas y repentinas reinvidicaciones. Pero, aunque todos los caciques de Cajamarca reconocieron a Chup Lingón como cacique principal de las Siete Guarangas, él no tardó en mostrar su incapacidad para gobernar. Entonces, el corregidor Diego de Salazar nombró a Pedro Malcaden, cacique de la guaranga de Malcaden, como cacique principal de las Siete Guarangas (Ramírez, 2002). Al morir este, en su testamento, devolvió el cacicazgo a Luis Carua Rayco27, hijo de Melchior. Sin

27 Este Luis Carua Rayco murió en 1607 y no debe ser confundido con su nieto, Luis Carua Rayco, confirmado en el cacicazgo de Cajamarca en 1635 por el conde de Chinchón. Véanse los testamentos de Luis Carua Rayco (ADC, leg. 31, f. 618, 30- 4-1607), Felipe Carua Rayco (ADC, leg. 34, f. 610, 27-10-1627) y Luis Carua Rayco (ADC, leg. 78, f. 1, 4-1-1636). Ramírez (2006) llama la atención sobre la confusión probable que cometemos en la identificación de los caciques si nos atenemos a la similitud de los nombres. Sugiere que al heredar un cargo, el Cacique andino heredaba también el nombre del antecesor así como el sitio que este ocupaba en los vínculos de parentesco. 
embargo, Sebastián Nina Lingón, hijo de Pedro Angas Napón y cuñado de Melchior Carua Rayco28, reclamó para sí el cacicazgo a finales de los años 1570.

Empezó entonces una lucha entre los herederos de Felipe Carua Rayco y los herederos de Angas Napón sobre el cacicazgo de las Siete Guarangas. Al final, los descendientes de Chup Tongo llegaron a mantenerse en el cacicazgo principal de Cajamarca o Siete Guarangas durante todo el siglo XVII, y aún más adelante. La continuidad se aseguró en el siglo XVII por vía testamentaria y vía de designación, en el cacicazgo principal de Cajamarca desde Felipe Carua Rayco, primer Cacique cristiano, como lo muestra el cuadro siguiente:

\begin{tabular}{|c|c|c|c|}
\hline $\begin{array}{l}\text { Nombre del } \\
\text { Cacique }\end{array}$ & $\begin{array}{l}\text { Fechas del } \\
\text { cargo }\end{array}$ & Tipo de legitimidad & Nombre de su mujer \\
\hline Felipe Carua Rayco & $1538-1543$ & $\begin{array}{l}\text { Designado por el encomendero } \\
\text { Melchor Verdugo y descendiente del } \\
\text { cacique Carua Tongo }\end{array}$ & $?$ \\
\hline $\begin{array}{l}\text { Melchior Carua } \\
\text { Rayco }\end{array}$ & $1563-1567$ & $\begin{array}{l}\text { Hijo del precedente. Confirmado por } \\
\text { el Corregidor. Despojado por el Dr. } \\
\text { González Cuenca }\end{array}$ & $\begin{array}{l}\text { Magdalena Cabus } \\
\text { Lachos }\end{array}$ \\
\hline Luis Carua Rayco & $?-1607$ & $\begin{array}{l}\text { Hijo del precedente. Designado } \\
\text { por vía del testamento de Pedro } \\
\text { Malcaden }\end{array}$ & Ana Cossa Pissit \\
\hline Felipe Carua Rayco & $1607-1627$ & $\begin{array}{l}\text { Hijo del precedente. Quedó hasta su } \\
\text { muerte }\end{array}$ & Clara Cabus Lachos \\
\hline Luis Carua Rayco & $1627-1636$ & $\begin{array}{l}\text { Hijo del precedente. Quedó hasta su } \\
\text { muerte pero fue confirmado por el } \\
\text { Virrey sólo en } 1635\end{array}$ & Ana Cabus Lachos \\
\hline $\begin{array}{l}\text { Sebastián Carua } \\
\text { Rayco }\end{array}$ & $1636-1659$ & $\begin{array}{l}\text { Tío del precedente. Confirmado por } \\
\text { el Corregidor y el Virrey }\end{array}$ & Fabiana Lachos \\
\hline $\begin{array}{l}\text { Melchior Carua } \\
\text { Rayco }\end{array}$ & $1661-1697$ & $\begin{array}{l}\text { Hijo del precedente. Era menor } \\
\text { de edad cuando su padre murió. } \\
\text { Confirmado por el Corregidor }\end{array}$ & Antonia Lobo \\
\hline Luis Carua Rayco & 1697 & Hermano del precedente. & Juana de Valdes \\
\hline
\end{tabular}

Fuente : testamentos de Melchior Carua Rayco (1565) in Ramírez (1998); Luis Carua Rayco (1607); Felipe Carua Rayco (1627); Luis Carua Rayco (1636). El testamento en virtud de poder de Sebastián Carua Rayco (1659); testamento de Melchior Carua Rayco II (1697) in ADC, protocolos notariales.

Las funciones de los caciques principales de Cajamarca, según los testamentos de los Carua Rayco, consistían en tratar directamente con los indios del común. Tenían la capacidad de cobrar el tributo, apoyándose para ello en una red de cobradores, de recoger los hombres para la mita (servicio personal), de dar justicia a los indios mediante el amparo de las tierras. Sin embargo, la contra parte la constituía la responsabilidad que les incumbía en el pago del tributo. En 1625, el Corregidor había mandado encarcelar a Felipe Carua Rayco y a otros caciques principales y mandones porque no habían pagado el tributo. Algunos testigos aseguraban que desde la cárcel era imposible acudir a la cobranza del tributo «por ser necesario hazer muchas diligencias con los yndios que los deuen y aun con ello se dificulta en muchas ocasiones pero estando fuera de la cárcel les apremiarán y podrán

28 Magdalena Cabus Lachos, mujer legítima de Melchior Carua Rayco era hermana de Sebastián Nina Lingón. Véase testamento de Felipe Carua Rayco, 1627 (ADC, leg. 34: f. 610). 
hazer las dichas diligencias con ellos con más facilidad que estando presos» (AGN, Derecho indígena, L. 6, c. 78). Por lo visto, solo los caciques, respetados y temidos por sus indios, podían llevar a cabo esta tarea. El problema revelado por este documento de 1625 y confirmado por otro de 1664 es que la cobranza del tributo nunca fue tarea fácil. Los caciques y mandones de pachacas, o ayllus, no alcanzaban a pagar un tributo que siempre decían ser demasiado elevado. Huían a las montañas, y gracias a la complicidad de los alcaldes de los pueblos, no les podía encontrar fácilmente (AGN, Derecho indígena, L. 6, c. 78)29.

En el documento de 1664, el cacique Melchior Carua Rayco, bisnieto de Felipe, está también en prisión por no haber pagado. De nuevo, afirma que son necesarios mucha digilencia y mucho tiempo para la cobranza. Subraya además el hecho de que más de 600 indios se ausentaron de la villa de Cajamarca, y que los cobradores le seguían debiendo plata. No obstante estas consideraciones prácticas, el Corregidor, como en 1625, sancionó a Melchior Carua Rayco, el cacique principal de las Siete Guarangas.

Por lo tanto, el límite al poder de los Carua Rayco parece haber sido la presencia, a partir del siglo XVII, de un nombrado «Cacique gobernador de Cajamarca» designado por el Corregidor con el objetivo de cobrar el tributo, por el fracaso en este cometido del Cacique principal. Éste debía entregar al Cacique Gobernador la paga de los tributos. Este caso revela la relación triangular entre estos dos caciques y el Corregidor, porque es este último quien está encargado de la «superintendencia universal» de su Corregimiento (AGI, Lima 171: f. 18). Tiene entonces que designar a alguien competente para cobrar el tributo. Sin embargo, la elección que hicieron los corregidores para designar a los caciques gobernadores no es debida al azar, o únicamente a la competencia notoria de algunos personajes, sino también a su relación compleja y antigua con los Carua Rayco.

\section{ASTO QUIPAN, CACIQUE GOBERNADOR DE LAS SIETE GUARANGAS}

El Gobernador era un Cacique por interín que actuaba como Cacique durante la ausencia, la minoría de edad o la enfermedad de un Cacique principal30. Podía ser nombrado por el Corregidor. El papel del poder colonial de los españoles no se limitaba a la validación formal de la elección de los caciques según sus competencias. En efecto, escogieron como caciques gobernadores a los enemigos históricos de los Carua Rayco, aquellos descendientes de Cristóbal Xulca Poma quien había apoyado a Chup Lingón cuando despojó a Carua Rayco en el año 1567. A principios del siglo XVII, un descendiente de Cristóbal Xulca Poma, Carlos Xulca Poma, casado con María Chup Lachos fue Cacique Gobernador de la provincia de Cajamarca. No era Cacique principal, sino más bien Cacique Gobernador, «por Su Magestad», según su testamento. Aunque no sabemos desde cuánto tiempo era Cacique Gobernador, dictó su testamento en 1630. No tuvo hijos, así que no instituyó ningún

${ }^{29}$ En el documento del archivo de 1625 el juez comisionado, Antonio Pérez de las Marinas, se presenta en el pueblo de San Pablo para embargar los bienes del Cacique, donde el alcalde don Miguel Carua Yalli le informa que el Cacique lleva ausente varios días. Entonces, el juez comisario decide embargar los bienes del Cacique directemente en su casa pero cuando llega a la casa del Cacique, no da ni con el Cacique ni con sus bienes (AGN, Derecho indígena, L. 6, C. 78).

30 Díaz Rementería (1977: 429: «la expresión “cacique gobernador” nace a consecuencia de la titularidad conjunta de cacique y de gobernador que coincide... en el indio que siendo titular legítimo de la dignidad cacical reuniera la capacidad necesaria para ejercer las funciones de gobierno...»; y, 43: «gobernador será por tanto aquel indio que considerado capaz por la autoridad competente para ejercer el gobierno de una comunidad como tal reciba la jurisdicción necesaria mediante designación y título. Y siempre, recordémoslo, que no exista cacique capaz». 


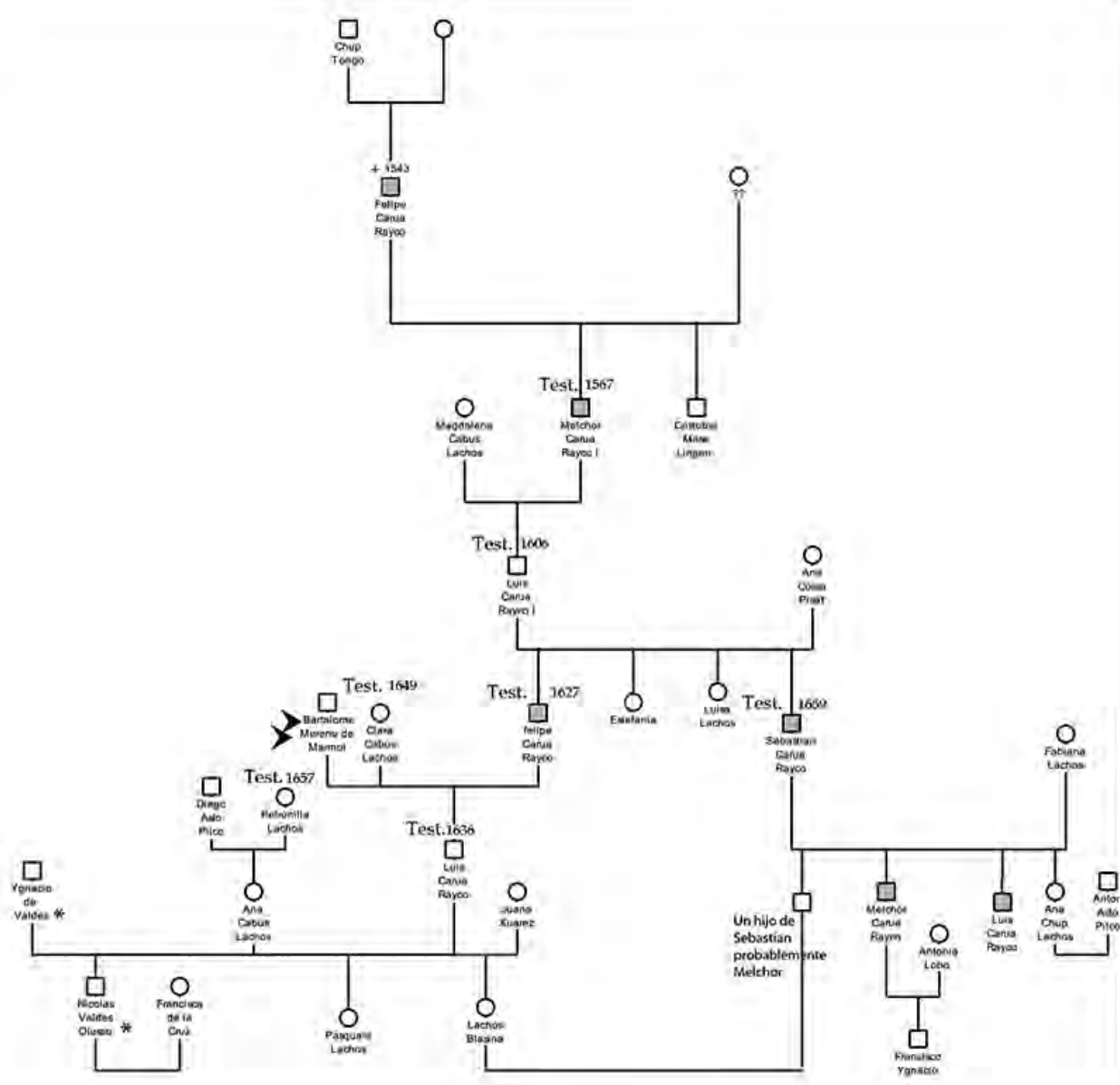

Leyenda

Caciques de las

Siete Guarangas

Protector de Naturales

Secundo matrimonio

Español

Fecha del testamento en el Archivo Departamental de Cajamarca 
heredero. Sin embargo, su cuñado, Gabriel Asto Quipan, le sucedió en el cargo. Gabriel era hijo de Diego Asto Pilco, o Quipan, hijo de Pedro Angas Napón, o sea sobrino de Sebastián Nina Lingón, también enemigo de Carua Rayco. Luego el hijo de Gabriel, Juan Bautista Asto Quipan fue cacique gobernador de la provincia de Cajamarca hasta fines del siglo.

Juan Baptista Asto Quipan parece haber vivido mucho tiempo, por ser ya tutor de Melchior Carua Rayco a fines de los años 1650, hasta fines de los años 1690, lo que representa unos cuarenta años de poder en el corregimiento de Cajamarca. Además Juan Bautista Asto Quipan, quien logró ostentar el título militar español de maestre de campo31, era hombre duro y litigioso. Los indios dijeron que era influyente en la justicia de esta villa, o sea con el Corregidor, y especialmente con el teniente de corregimiento don Domingo de Quevedo (AGI, Lima 171).

\begin{tabular}{|c|c|c|c|c|}
\hline $\begin{array}{l}\text { Nombre del } \\
\text { Gobernador }\end{array}$ & $\begin{array}{c}\text { Fechas del } \\
\text { cargo* }^{*}\end{array}$ & Lazo de parentesco & Título & $\begin{array}{l}\text { Nombre de } \\
\text { su mujer }\end{array}$ \\
\hline $\begin{array}{l}\text { Carlos Xulca } \\
\text { Poma }\end{array}$ & $?-1630$ & - & $\begin{array}{l}\text { Cacique gobernador de } \\
\text { las Siete guarangas }\end{array}$ & $\begin{array}{l}\text { María Chup } \\
\text { Lachos }\end{array}$ \\
\hline $\begin{array}{l}\text { Gabriel Asto } \\
\text { Quipan }\end{array}$ & $1630-1657$ & $\begin{array}{l}\text { Cuñado del } \\
\text { precedente (hermano } \\
\text { de María Chup } \\
\text { Lachos) }\end{array}$ & $\begin{array}{l}\text { Cacique gobernador de } \\
\text { las Siete Guarangas }\end{array}$ & - \\
\hline $\begin{array}{l}\text { Francisco Gabriel } \\
\text { Asto Quipan }\end{array}$ & $?-1699$ & Hijo del precedente & 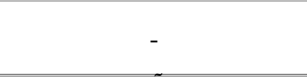 & - \\
\hline $\begin{array}{l}\text { Juan Baptista } \\
\text { Asto Quipan }\end{array}$ & $1659-1701$ & $\begin{array}{l}\text { Hermano del } \\
\text { precedente }\end{array}$ & $\begin{array}{l}\text { Cacique de Nalep; } \\
\text { Cacique gobernador } \\
\text { de las Siete Guarangas; } \\
\text { tutor de Melchior } \\
\text { Carua Rayco a la } \\
\text { muerte de su padre en } \\
\text { 1659; encargado de la } \\
\text { cobranza del título por } \\
\text { el Corregidor en } 1664 ; \\
\text { tiene el título de maestre } \\
\text { de campo }\end{array}$ & $\begin{array}{l}\text { María de } \\
\text { Llanos }\end{array}$ \\
\hline
\end{tabular}

Fuentes: testamento de Carlos Xulca Poma (1630); testamento de María Chup Lachos (1635), in ADC, protocolos notariales.

* fechas según las de los testamentos en el ADC.

Aunque Fabiana Lachos, mujer de Sebastián Carua Rayco y madre de Melchior Carua Rayco, era hija de su hermano Francisco Gabriel Asto Quipan, Juan Baptista Asto Quipan intentó por lo menos dos veces quitarle el título de Cacique a Melchior Carua Rayco, así como su casa de Cacique en Cajamarca32. Una primera vez en 1661, alegando que Sebastián Carua Rayco, padre de Melchior, no había podido pagar unas deudas tributarias, Asto Quipan puso en adjudicación la casa de vivienda de Melchior Carua Rayco (ADC, serie Corregimiento, testimonios s/f.). Este último cuestionó el precio (300 pesos), demasiado

31 El corregidor don Antonio de Quintanilla, bien informado de los riesgos marítimos en las costas del virreinato, formó un verdadero ejército cajamarquino, listo para intervenir en caso necesario. Posiblemente en esta ocasión, y por los lazos que tenían entre sí, Juan Baptista Asto Quipan tuvo la oportunidad de obtener el título (AGI, Escribanía de Cámara, 535 B. Juicio de residencia de don Antonio de Quintanilla).

32 Para las herencias sobre cacicazgos, véase Lavallé, 2004. 
bajo (dijo que valía 1000 pesos), negando el hecho de que una deuda tributaria de su padre pudiera ser cobrada de los bienes heredados por el hijo cuando este tenía la posibilidad de pagar la deuda con sus propios bienes muebles. Las alegaciones de Carua Rayco permiten en este caso ver la obsesión de Asto Quipan por hacerse con la casa de caciques, símbolo de la implantación de los Carua Rayco en el centro de la villa y de la memoria de los cajamarquinos y, sin lugar a duda, un elemento de máximo prestigio y de legitimación del poder étnico por recordar el dominio de los incas33. Un dibujo de la serie de Martínez Compañón da fe de que dicha casa, con sus fuertes muros incaicos, seguía siendo la morada del cacique de las Siete Guarangas por el año de 1785.

Pero, a principios de 1664, el corregidor don Antonio de Quintanilla nombró a Juan Baptista Asto Quipan cobrador del tributo de las Siete Guarangas para los tercios de san Juan de 1664, en lugar de Melchior Carua Rayco que fracasó en su tarea y que quedaba deudor de los tercios anteriores. A este último, le había puesto en la cárcel unos semanas antes «en el cepo con un par de grillos», de donde obviamente no podía proceder a la recogida de los tributos. Denunció estas condiciones afrentosas, «como si fuera indio particular siendo Cacique principal que es de los más nobles deste reyno» (f. 6).

Según los argumentos esgrimidos por Melchior Carua Rayco en este litigio, Asto Quipan no quiso saber nada de la paga de los tributos, la única cosa que parecía interesarle era que Carua Rayco fuese despojado de su cargo de cacique de las Siete Guarangas, y que él fuese nombrado Gobernador para entonces quedarse como cacique de las Siete Guarangas. Además, alegaba Carua Rayco que los indios de Cajamarca eran hombres de buen crédito y que el hecho de nombrar a su enemigo como cobrador le iba a discreditar totalmente. De esta forma, al repartir la cobranza de los tercios entre Melchior Carua Rayco y Juan Baptista Asto Quipan, el Corregidor limitaba los poderes respectivos de los dos caciques enemistados. El corregidor Antonio de Quintanilla explicó que Juan Baptista Asto Quipan era persona «de conocida y notoria satisfacción y sin duda alguna la más a propósito se pudiera allar para dicho ministerio encargarsele sin atender la enemistad que refiere...» (AGI, Lima 171: f. 24).

Sin embargo, puede haber sido una estrategia secular del poder colonial para neutralizar a estos caciques, sin interferir más, por lo menos en aparencia, en los asuntos de los demás. En efecto, hubiera sido posible nombrar a Francisco Gabriel Asto Quipan, hermano de Juan Baptista Asto Quipan y abuelo de Melchior Carua Rayco, el cual tenía buena relación con su nieto34. Pero, los españoles mantuvieron la ambigüedad entre los jefes étnicos. Melchor Carua Rayco subrayó que «finalmente en los tiempos presentes solo se tiene por buen Gobernador el que prefiere las conbeniencias de los corregidores al alibio de los indios» (f. 81v).

Ninguno de los dos era ya el jefe absoluto pero cada uno tenía autoridad y conservaba un acceso privilegiado a la fuerza de trabajo que eran los indios del común35. Pero eso no hubiera sido posible sin la red de caciques cobradores constituida por el tercer tipo de caciques.

33 Porque era la casa que lindaba en la plaza de armas con la casa del Corregidor, y que llaman «casa del ynga». Se trata de la casa que hoy en día se llama Cuarto del Rescate, donde el Inca Atahualpa señaló el listón que alcanzarían los tesoros que entregaría a los conquistadores (Martínez Compañón, 1985 [1785] vol. 1: f. 98r).

34 Francisco Gabriel Asto Quipan era hermano mayor de Juan Baptista Asto Quipan. En 1664, es un anciano impedido, «que por su ympedimiento no es posible pueda acudir a las dichas cobranzas con la puntualidad brevedad y cuidado que el casso requiere...» (AGI, Lima 171: f. 107v). Otro argumento esgrimido contra Francisco Gabriel Asto Quipan, es que cuando tenía a su cargo la cobranza de los indios de Guzmango, causó muchos rezagos. Sobre esta dinastía de caciques, ver la advertencia de Ramírez (2006) evocada en la nota 27.

$35 \mathrm{El}$ antiguo corregidor de Cajamarca, Martín de la Riva Herrera, recomienda a Juan Baptista Asto Quipan al Corregidor en funciones, don Antonio de Quintanilla, porque Juan Baptista Asto Quipan fue cobrador de las Siete 


\section{SER CACIQUE Y PORTARSE COMO TAL}

Cada pueblo tenía sus cobradores, nombrados por el cacique principal de las Siete Guarangas (AGI, Lima 171). Se trataba en realidad de una carga más que de un cargo: el papel de cobrador de tributos de indios implicaba riesgos porque la carga del ingreso de la tasa pesaba sobre los caciques, sus patrimonios y sus personas. Las amenazas que implicaba, en particular el embargo de los bienes o la cárcel, hacían que el riesgo de esta responsabilidad radicaba en el tributo mismo, y tuvieron los cobradores que adaptarse a las nuevas concepciones y valores españoles para mantener algo de poder. La figura tradicional del Cacique por lo tanto evolucionó a lo largo de los siglos XVII y XVIII, y algunos de ellos se transformaron ante todo en recaudadores de tributo (O'Phelan Godoy,1997; Pease, 1992), formando una impresionante red de cobradores. En efecto, muchos de los caciques, a la hora de dictar sus testamentos, estaban adeudados con su Cacique superior o con el Cacique Gobernador principal, por los tributos de los años anteriores, y dieron una lista completa de los nombres de sus cobradores para «descargo de su conciencia».

Siempre habían sido considerados responsables por los retrasos, la falta de numerario, etc... Varias veces habían sido encarcelados porque «sus indios» no pagaban o no podían pagar los tributos, como occurrió en 1625, cuando el corregidor Juan de Guzmán mandó encarcelar a diez caciques de Cajamarca, entre estos a Felipe Carua Rayco (AGN, Derecho indígena, L. 6, c. 78), o también en 1664.

El cobrador era responsable de la suma de plata que le tocaba cobrar. Cuando no podía pagar el tributo, tenía que pedir al Cacique superior un préstamo. Se volvía deudor de éste, quien a su vez era deudor del siguiente. La red de cobradores se parece a una red de deudas. Cada uno, según sus relaciones, trataba de encontrar el dinero para pagar el tributo debido por los indígenas. Los indios urbanos tuvieron entonces la posibilidad de entrar en esta red, como prestamistas de dinero a los caciques principales de las pachacas y guarangas que vivían en la villa de Cajamarca o en los pueblos de las Siete Guarangas.

En 1672, Diego Asto Lingón, Cacique cobrador de la pachaca de Guzmango del pueblo de San Pablo, declaró (ADC, Protocolos notariales, L. 101: f. 750) que estaba a su cargo la cobranza de tributos desde hacía 22 años según la numeración de indios que le había entregado el Gobernador. Los recibos en su poder daban fe de lo que había cobrado y enterado hasta la fecha al Gobernador. Sin embargo, confesó no haber conseguido cobrar el tributo en su totalidad: le faltaban 383 pesos y 3 reales. Reconoció haber suscrito una escritura de endeudamiento con Juan Baptista Asto y declaró también que dejó nombrados los indios que le seguían debiendo sus tributos. Añadió que lo que se podía cobrar todavía se reintegrase al Gobernador y que éste mandara cobrar el resto, «sin que se me quede a ser cargo ni cobrar de mis hijos ni bienes». No sé exactamente qué valor tiene esta precaución testamentaria en la que Diego Asto Lingón pide expresamente que sus hijos y sus bienes no sean deudores del Gobernador, pero revela que los cobradores trataban de salir del círculo infernal de las deudas. Esta solicitud reinvidica un punto interesante: el que la obligación de los herederos en la paga del tributo debido por su padre se limitara a los bienes dejados por el padre y que no pueda cargarse sobre los bienes propios del hijo.

En definitiva, emerge una cadena de responsabilidades que van del Corregidor al cobrador, pasando por los caciques principales, y a veces y por intrusión del Corregidor, por los gobernadores-cobradores. Sin embargo, tengo la intuición de que unos, para pretender al

Guarangas «sin causar resagos por su gran zelo, sin que aya abido queja ninguna de cassiques e yndios ni otras personas como es notorio prosediendo siempre con grand fedelidad y çelo en el servicio de Su Magestad» (f. 86v). Sobre la «doble autoridad», véase Puente Brunke (1992). 
cacicazgo, empezaron a cobrar el tributo o llegaron a ser nombrados cobradores, así como lo hizo Juan Baptista Asto Quipan a su nivel de gobernador de las Siete Guarangas. En efecto, ya que los caciques no debían cumplir con las obligaciones personales (Recopilación de Leyes de Indias, Ley XVIII, Título V, Libro VI ), algunos primos o sobrinos de caciques trataron de beneficiarse de la exención (Díaz Rementería, 1977)36. Y, al final del siglo XVII, varios caciques, principales y mandones eran denunciados en una provisión del Virrey fechada del 31 octubre de 1694: en los repartimientos de Cajamarca, había muchos indígenas, que por decir ser hijos y parientes de caciques no pagaban tasa, ni cumplían el servicio personal. Las tasas cargaban sobre indios pobres que «habian de ser pobres en pesso de ello». El Virrey mandó que solo los hijos mayores de los caciques y mandones sean excusados de las obligaciones personales. Solo ellos pueden suceder con derecho en el cacicazgo de su padre y su casa. Son caciques, lo recuerda el Virrey, «por sucesión y derecho de sangre desde la gentilidad de ellos», y deben gozar del privilegio de exención de la nobleza. Tengo el ejemplo de Juan Lulimosa, sobrino del cacique de Guzmango Francisco Asto Pilco (1694). Intentó beneficiarse de este privilegio, por no tener hijo el Cacique. Juan Lulimosa trató de probar que era descendiente de Pedro Angas Napón y suplicó que se le diera la posesión del cacicazgo por ser hijo, nieto y descendiente de Cacique. Así, para estos caciques de tercer tipo, la fama de Cacique era imprescindible: uno debía haber cobrado el tributo a la vista de todos, y ser notable descendiente, además de hijo mayor, de caciques conocidos como tales por los españoles. La estirpe genealógica también debía ser ilustre porque Lulimosa trató de establecer su ascendencia con Angas Napón.

Los caciques principales de las guarangas y pachacas de la provincia de Cajamarca en el siglo XVII, la mayoría con casas en la traza de la villa, formaban parte de una élite urbana preocupada por asuntos financieros, pero que conservaba vínculos estrechos con «sus indios», que podían movilizar gracias a la red de cobradores, con quienes tenían cuentas pendientes.

\section{CONCLUSIÓN}

La administración española, burocrática y compleja, tenía dificultades frecuentes para tomar en consideración lo que hoy en día llamaríamos la «realidad del terreno»37. Los gobiernos locales, es decir el Corregidor y los alcaldes no eran una proyección, al nivel local, del poder real. Al contrario, eran entidades autónomas que tenían la capacidad de negociar su funcionamiento entre sí y con la Corona. En un asentamiento como Cajamarca, un pueblo de indios tranformado en villa, se sentaban muchas personas a la mesa de negociaciones: cabildo de indios, caciques, y Corregidor, es decir las distintas autoridades indígenas locales y el poder español. Las dinámicas que resultan de estas tensiones nos llevan a tomar en consideración cada entidad y sus motivaciones propias. En Cajamarca, el Corregidor usaba una estrategia clásica, la de la división, para neutralizar a los caciques nobles, dejándoles un acceso a la red de cobradores, que constituía una piedra angular del sistema colonial económico de la provincia de Cajamarca.

\footnotetext{
36 Este hecho lo señala Díaz Rementería (1977: 44): «El cobrador de tributos podría ser cualquier indígena que, contando principalmente con los bienes de fortuna que se consideraban precisos para afianzar la totalidad de lo tasado a una comunidad concreta, recibiera por una autoridad, el corregidor, subdelegado tras la instauración del régimen de intendencias en el siglo XVIII, o el cacique gobernador, esa expresa función».

37 Glave (1998) recuerda que solo el virrey Francisco de Toledo había viajado fuera de Los Reyes.
} 


\section{Referencias citadas}

\section{Fuentes primarias}

AGI: Archivo General de Indias, Sevilla.

Escribanía de Cámara, 516 A; 535 B

Lima 303, 171

AGN: Archivo General de la Nación, Lima

Derecho indígena, Legajo 6, cuaderno 78

Títulos de propiedad, 1644, Legajo 34, cuaderno 649

Superior Gobierno, Legajo 4, cuaderno 45

ADC: Archivo Departamental de Cajamarca

Protocolos notariales

Corregimiento, subserie testimonios

ASFL: Archivo del Convento San Francisco de Lima

Registro $n^{\circ} 11$

\section{Fuentes segundarias}

AGUILERA ROJAS, J., 1994 - Fundación de ciudades hispanoamericanas, 395 p.; Madrid: Editorial MAPFRE.

BONET CORREA, A., 1978 - Le concept de plaza mayor en Espagne depuis le XVlème siècle. In: Forum et Plaza Mayor dans le monde hispanique, Vol. Fasc. IV (Chevalier, F., ed.): 79-105; París: Boccard. Recherches en sciences sociales.

CHARNEY, P., 1988 - El indio urbano: un análisis económico y social de la población india de Lima en 1613; Historica, XII-1: 5-33; Lima.

CHEVALIER, F., 1978 - La «Plaza mayor» en Amérique latine, espaces et mentalités. Un essai. In: Forum et Plaza Mayor dans le monde hispanique, Vol. Fasc. IV (Chevalier, F., ed.): 107-122; París: Boccard. Recherches en sciences sociales.

CUESTA, J. M., 1988 - Jaén de Bracamoros. Historia y Evangelización del siglo XVII, tome IV, 466 p.; Lima: Libreria Studium, Conycet.

DÍAZ REMENTERÍA, C. J., 1977 - El Cacique en el Virreinato del Perú: Estudio HistóricoJurídico, 260 p.; Sevilla: Publicaciones de la Universidad de Sevilla. Seminario de antropología americana, 15.

ESPINOZA SORIANO, W., 1967 - El primer informe etnológico de Cajamarca, año de 1540, 37 p.; Lima: Revista peruana de cultura.

ESPINOZA SORIANO, W., 2002 - Españoles en la villa de Cajamarca a mediados del siglo XVII. In: Sobre el Perú: homenaje a José Agustín de la Puente Candamo (O. Holguín Callo \& C. Gutiérrez Muñoz, eds.): 511-530; Lima: Pontificia Universidad Católica del Perú.

FIGUEROA LUNA, G., 1993 - La visita de 1657 en Chota y Bambamarca. Comunidades, vecinos y tenencia de la tierra. In: Sociedad de investigación de la cultura y arte del Norte. «Proyecto los Pueblos de indios de Cajamarca»: 1-36.

GLAVE, L. M., 1998 - De Rosa y espinas: economía, sociedad y mentalidades andinas, siglo XVII, 387 p.; Lima: IEP, BCRP. Estudios Históricos 24.

GUAMAN POMA DE AYALA, F., 1936 [1613] - Nueva Coronica y Buen Gobierno (Codex péruvien illustré), xxviii +1167 p.; París: Institut d'Ethnologie. 
GUTIÉRREZ, R. (ed.), 1992 - Estudios sobre urbanismo iberoamericano. Siglos XVI al XVIII, 464 p.; Sevilla: Junta de Andalucía.

HAMPE MARTÍNEZ, T., 1986-1987 - Notas sobre la población y tributo indígena en Cajamarca (primera mitad del siglo XVII). Boletín del Instituto Riva-Agüero, 14: 65-81.

KUBLER, G., 1957 - Ars Hispanae. Arquitectura de los siglos XVII y XVIII, 379 p.; Madrid: Editorial Plus-Ultra.

LAVALLÉ, B., 2004 - Caciques intrusos, pouvoir colonial et légitimité caciquale dans I'Audience de Quito au XVIIIe siècle. In: Les autorités indigènes entre deux mondes, Solidarité ethnique et compromission coloniale (B. Lavallé, ed.): 159-176; París: Centre de Recherche sur l'Amérique Espagnole Coloniale, Université de la Sorbonne Nouvelle, Paris III. Travaux et Documents $n^{\circ} 5$.

MARTíNEZ COMPAÑÓN, B., 1985 [1785] - Trujillo del Perú; Madrid: Cultura Hispánica. 9 tomos, ed. facsímil.

MINCHOM, M., 1994 - The People of Quito. Change and Unrest in the Underclass, 297 p.; Boulder, Oxford: Westview Press. Dellplain Latin American Studies, $n^{\circ} 32$.

MONNET, J. (ed.), 1999 - Ville et pouvoir en Amérique latine. Les formes de l'autorité, 190 p.; París: I'Harmattan. Culture et politique.

MUSSET, A., 2002 - Villes nomades du nouveau monde, 397 p.; París: Éd. de l'École des hautes études en sciences sociales.

NOACK, K., 2001 - Los caciques ante el notario. Transformaciones culturales en el siglo XVI. In: América bajo los Austrias: economía, cultura y sociedad (Noejovich, H.): 191-204; Lima: Pontificia Universidad Catolica del Perú.

O'PHELAN GODOY, S., 1997 - Kurakas sin sucesiones: del cacique al alcalde de indios (Perú y Bolivia 1750-1835), 104 p.; Cuzco: Centro Bartolomé de Las Casas.

PEASE, F., 1992 - Curacas, reciprocidad y riqueza, 208 p.; Lima: Pontificia Universidad Católica del Perú.

PEREYRA PLASENCIA, H., 1996 - Bosquejo histórico del corregimiento de Cajamarca. Boletín del Instituto Riva-Agüero, $\mathbf{n}^{\circ}$ 23: 173-239.

POLONI-SIMARD, J., 1999 - Problèmes et tentatives d'identification des métis à travers la documentation coloniale. L'exemple de Cuenca. In: Transgressions et stratégies du métissages en Amérique coloniale (Lavallé, B., ed.): 11-31; París: Presses de la Sorbonne Nouvelle.

PUENTE BRUNKE, J. de la, 1992 - «Los vasallos se desentrañan por su Rey»: notas sobre quejas de curacas en el Perú del siglo XVII. Anuario de Estudios Americanos, LV-2 (julio-diciembre): 459-473.

RAMíREZ, S. E., 1998 - Rich Man, Poor Man, Beggar Man, or Chief: Material Wealth as a Basis of Power in Sixteen-Century Peru. In: Dead Giveaways. Indigenous Testaments of Colonial Mesoamerica and the Andes (Kellogg, S. \& Restall, M., eds.): 215-248; Salt Lake City: University of Utah Press.

RAMÍREZ, S. E., 2001 - El concepto de «comunidad» en el siglo XVI. In: América bajo los Austrias: economía, cultura y sociedad (Noejovich, H., ed.): 181-189; Lima: Pontificia Universidad Católica del Perú.

RAMÍREZ, S. E., 2002 - Don Melchior Caruarayco. A Kuraka of Cajamarca en el SixteenthCentury Peru. In: The Human Tradition in Colonial Latin America, vol. 5 (Andrien, K.J., ed.): 22-34; Oxford: SR Books, Lanham, MD., The Human Tradition around the World.

RAMÍREZ, S.E., 2006 - Historia y memoria: la construcción de las tradiciones dinásticas andinas. Revista de Indias, LXVI-236 (enero-abril): 13-56. 
RAVINES, T. (ed.), 1986 - Noticias de Cajamarca, 144 p.; Cajamarca: Instituto Nacional de Cultura Cajamarca Fondo Editorial.

REMY SIMATOVIC, M. d. P., 1992 - La visita a Cajamarca de 1571-72/1578. In: Las visitas a Cajamarca 1571-72/1578, Vol. 1 (Remy Simatovic, M. d. P. \& Rostworowski de Diez Canseco, M., eds.): 37-83; Lima: Instituto de Estudios Peruanos.

RECOPILACIÓN DE LEYES DE LOS REINOS DE LAS INDIAS, 1681 - Disponible en http://www.congreso.gob.pe/ntley/LeylndiaP.htm

RICARD, R., 1947 - la Plaza mayor en Espagne et en Amérique espagnole. Annales. Economies Sociétés et Civilisations, 4: 433-438.

SILVA SANTISTEBAN, F., 1986 - Cajamarca en la historia del Perú. In: Historia de Cajamarca, volume 1 (F. Silva Santisteban, R. Ravines \& W. Espinoza Soriano, eds.): 9-28; Cajamarca: Instituto Nacional de Cultura.

VARGAS UGARTE S. J., R., 1986 - Matías Pérez Palomino, alarife de la iglesia de San Antonio de la villa de Cajamarca. In: Historia de Cajamarca, Vol. 3 (F. Silva Santisteban, W. Espinoza Soriano \& R. Ravines, eds.): 147-158; Cajamarca: Instituto Nacional de Cultura.

VÁSQUEZ DE ESPINOSA, A., 1969 [1628] - Compendio y descripción de las Indias occidentales, 577 p.; Madrid: Atlas. Biblioteca de Autores Españoles, n 231.

VAYSSIERE, B. \& LE FLEM, J.-P., 1978 - La Plaza mayor dans I'urbanisme hispanique. Essai de typologie. In: Forum et Plaza Mayor dans le monde hispanique, Vol. Fasc. IV (Chevalier, F., ed.): 43-78; París: Boccard. Recherches en sciences sociales.

ZAVALA, S. A., 1935 [1992] - La Encomienda Indiana, 1042 p.; México: Biblioteca Porrúa, 53. 